\title{
Multi-objective gearbox design optimization for xEV-axle drives under consideration of package restrictions
}

\author{
M. Hofstetter ${ }^{1} \mathbb{D} \cdot$ D. Lechleitner ${ }^{1} \cdot$ M. Hirz' $\cdot$ M. Gintzel ${ }^{2} \cdot$ A. Schmidhofer ${ }^{2}$ \\ Received: 23 April 2018 / Published online: 6 September 2018 \\ (c) The Author(s) 2018
}

\begin{abstract}
In the design process of electric powertrains, consisting of electric machine, gearbox and power electronics, the requirements regarding performance, package and costs are typically set on system level. This imposes that deduction of component requirements is not unique and component properties interfere with each other. As a component of the powertrain system, the gearbox represents a linking element between the electric machine and drive shafts to the wheels. Through this the available installation space of the gearbox shows manifold characteristics due to multiple possible motor- and power electronics variants as also versatile system installation positions and angles. This space can be utilized by different gearbox variants, which are characterized by gearbox-internal design parameters. They affect gear ratio, configuration of gear wheels, outer shape of the gearbox and therefore the package as well as efficiency and production costs. The high variability of gearbox design parameters and packaging-related aspects lead to a complex problem in the design process. In this context, the present contribution introduces a gearbox design optimization process to support decision-making in the early development phase. For given load-, lifetime- and package-requirements, the introduced differential-evolution-based process delivers design parameters for shafts, gears, bearings and their arrangement to handle efficiency, package and costs in a multi-objective manner. The results are represented by a Pareto front of gearbox designs variants, from which decision makers are able to choose the best and most suitable trade-off. The new approach is exemplarily demonstrated on a single-speed, two-stage helical gearbox with an integrated differential drive, which represents a common gearbox topology for xEV-axle drives.
\end{abstract}

M. Hofstetter

martin.hofstetter@tugraz.at

1 Graz University of Technology, Graz, Austria

2 Magna Powertrain GmbH \& Co KG, Traiskirchen, Austria 


\section{Multi-kriterielle Optimierung eines xEV-Getriebes unter Berücksichtigung von Bauraumeinschränkungen}

\section{Zusammenfassung}

Bei der Auslegung elektrischer Antriebsstränge, bestehend aus Elektromotor, Getriebe und Leistungselektronik, werden Anforderungen bezüglich Leistung, Bauraum und Kosten üblicherweise auf Systemebene gestellt. Dadurch ist die Ableitung der Komponentenanforderungen nicht eindeutig und Komponenteneigenschaften interferieren. Der verfügbare Bauraum für das Getriebe, welches das Verbindungselement zwischen Elektromotor und Antriebswellen der Räder darstellt, kann somit vielfältige Gestalt annehmen. Diese ist sowohl abhängig von den verwendeten Motor- und Leistungselektronikvarianten als auch von den Freiheitsgraden, die bei der Systemanordnung bestehen. Dieser Bauraum kann durch verschiedene Getriebevarianten genutzt werden, die durch getriebespezifische Gestaltungsparameter beschrieben werden. Diese beeinflussen beispielsweise Übersetzungsverhältnis, Verzahnungsparameter und äußere Gestalt bzw. Bauraumbedarf, sowie Effizienz und Herstellungskosten. Somit führen die hohe Gestaltungsvielfalt und bauraumbezogene Aspekte zu einem komplexen Problem im Entwurfsprozess.

In diesem Zusammenhang wird ein auf Differential-Evolution basierender, multi-kriterieller Getriebeoptimierungsprozess vorgestellt, um die Entscheidungsfindung in der frühen Entwicklungsphase zu unterstützen. Für gegebene Last-, Lebensdauer- und Bauraumanforderungen werden Auslegungsparameter für Wellen, Verzahnung, Lager und deren Anordnung generiert, um Effizienz, Bauraum und Kosten zu optimieren. Als Ergebnis liegt eine Pareto-Front von Getriebevarianten vor, aus denen Entscheidungsträger die bestgeeigneten Kompromisslösungen auswählen können.

Der neuartige Ansatz wird beispielhaft anhand eines zweistufigen Ein-Gang-Stirnradgetriebes mit integriertem Differentialgetriebe vorgestellt, das eine verbreitete Getriebetopologie für elektrische Antriebsachsen darstellt.

\section{Problem}

An electric powertrain-also known as eDrive-consists of the electric machine, the gearbox and the power electronics (Fig. 1a). It can be applied in fully electric vehicles or in axle-split hybrid electric vehicles [1]. The gearbox represents a linking element between electric machine and drive shafts to the wheels.

In the gearbox design process of a new eDrive (Fig. 2), several input parameters have to be considered [2], e.g.:

a. transmission ratio,

b. (range of) offset between input- and output shaft,

c. load spectrum and service life to guarantee reliability,

d. desired installation space.

Various gearbox variants are eligible to fulfill these requirements; each being characterized by gearbox-internal design parameters. They affect the main components (Fig. 1b) found in a gearbox, which are:

a. gear wheels,

b. shafts,

c. bearings,

d. a housing supporting this interior.

Each of these components influences the outer shape of the gearbox and therefore the package as well as the efficiency and production costs; also favorable noise, vibration and harshness (NVH) behavior is a key design goal (although not yet covered by the presented approach). The high variability of gearbox design parameters, conflict- ing design objectives and packaging-related aspects lead to a complex problem in the design process.

\section{Importance of system perspective}

The conventional design synthesis process implements heuristic synthesizing strategies at component level. Machine elements commonly found in gearboxes are well examined as isolated components. Acknowledged reference works such as [3] give detailed design recommendations on how to select the design parameters of a single component in order to achieve a certain design goal. This requires the application of design strategies at component level, which might lead to suboptimal results because of the limited capabilities of the applied synthesizing strategies. Many components coexist in the respective supersystem and their interactions also dictate the system properties. The synthesizing process must therefore not only consider isolated components but also their interactions in the system context. An illustrative example includes an exemplary efficiency optimization of a gearbox. An efficient gear design will generally favor high helix angles [3]. As a consequence, such a design induces high bearing loads, which in turn leads to high frictional losses in the bearings. This exemplary conflict outlines the importance of well-considered synthesizing strategies at component level, which can be eliminated by smart optimization algorithms supporting the design synthesis at the respective supersystem level. 
a

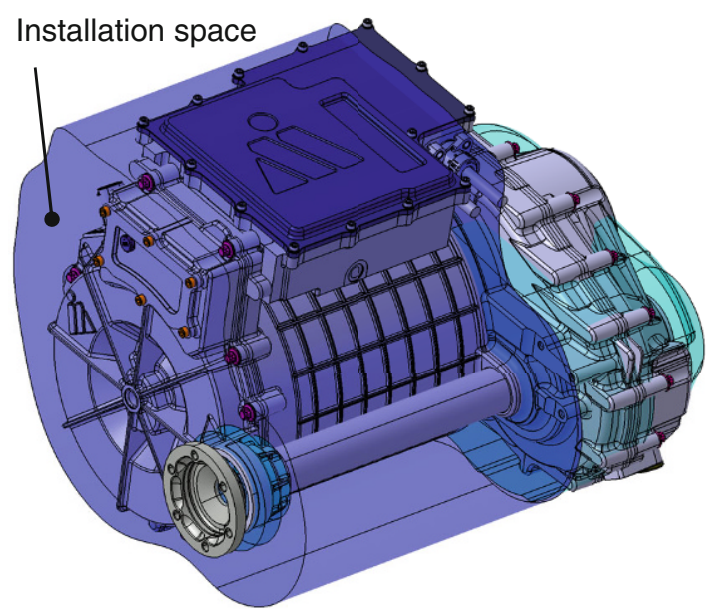

b

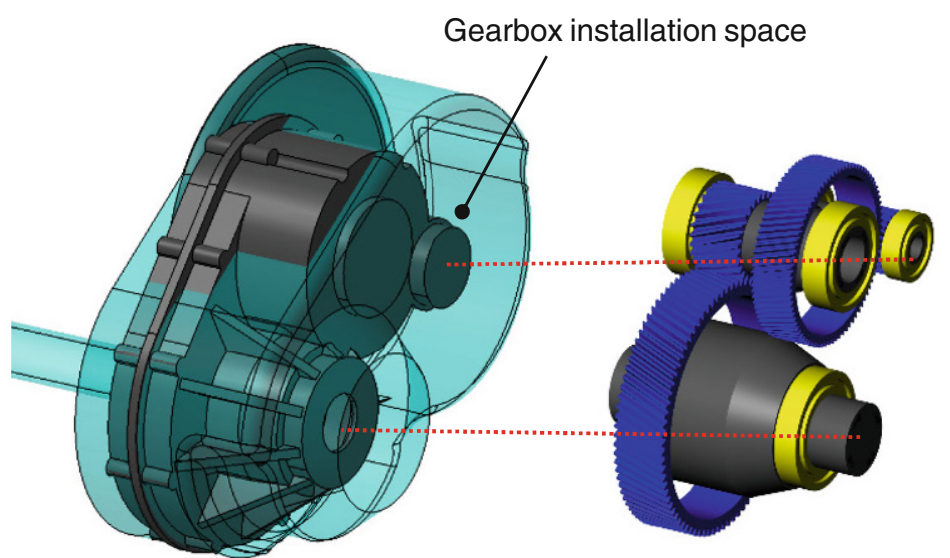

Fig. 1 Example of eDrive solution and gearbox interior a eDrive solution in desired installation space (transparent blue and turquoise) and gearbox-specific installation space (highlighted in transparent turquoise) b Generic gearbox model with corresponding desired installation space (left) and schematics of interior (right)

Fig. 2 Gearbox design problem

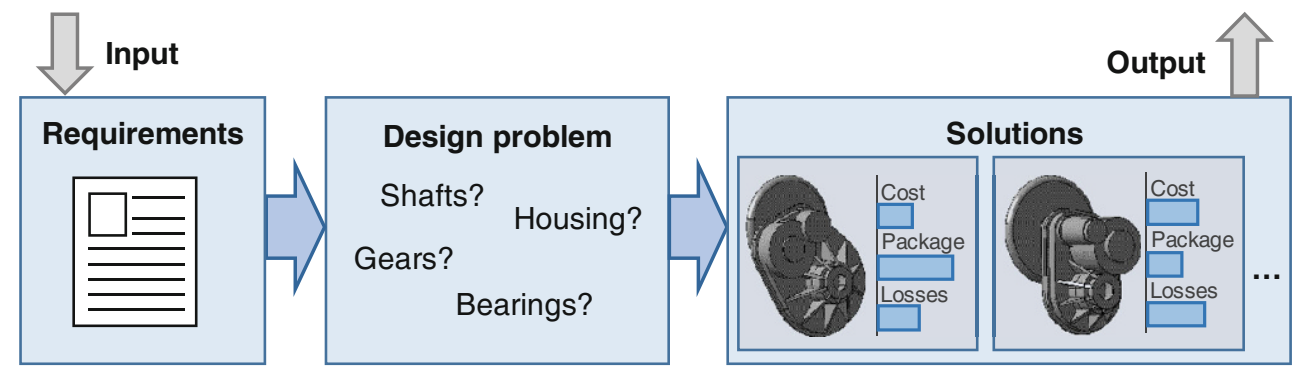

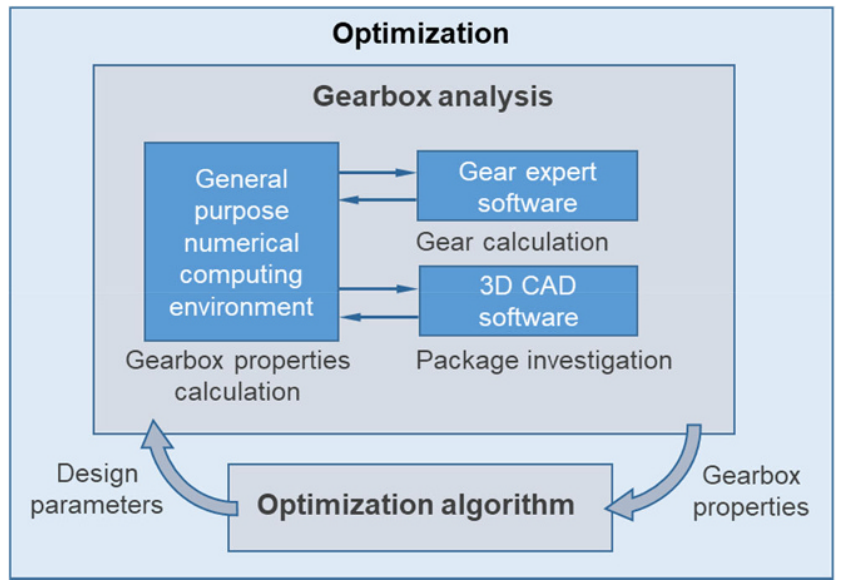

Fig. 3 Gearbox optimization as closed-loop of design parameter determination and gearbox analysis

\section{Approach}

The present contribution introduces a computer-aided gearbox design optimization process supporting the early development phase of gearboxes in eDrives. For given load, lifetime and desired installation space, the differential evo- lution-based [4] process (Fig. 3) delivers design parameters for shafts, gears, bearings and their arrangement to handle efficiency, package and costs in a multi-objective manner. In general, any objective derivable from the gearbox properties can be used as an optimization objective.

Since this methodology is focusing on the early development stage, specific detailed design characteristics, e.g. lubrication, deformation of the housing, acoustic behavior $(\mathrm{NVH})$, rotor stability and park lock integration are not covered by this design optimization. Nevertheless, these influences are essential for the design of successful gearbox solutions. They must be covered in a subsequent process where the expertise of an experienced gearbox manufacturer is vital to deal with the challenges. The introduced approach for holistic gearbox design is demonstrated on a single-speed, two-stage helical transmission with integrated differential drive, which represents a common configuration (Fig. 1b). Nevertheless, the introduced method can be applied for other gearbox architectures as well. 
Fig. 4 Visualization of gearbox design parameters; variables description in Table 1

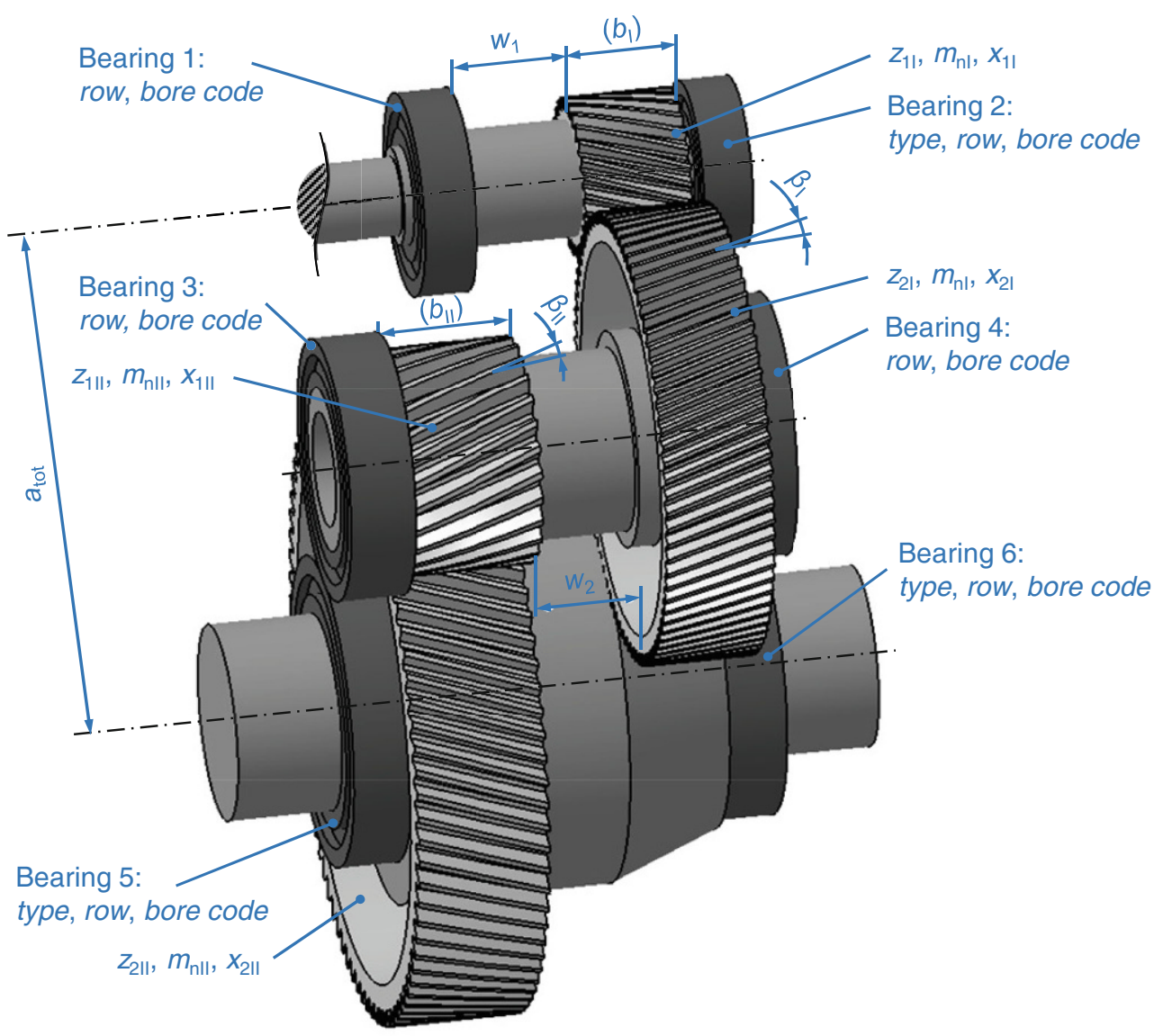

\section{Literature discussion}

The application of optimization algorithms to automate gearbox design has been addressed in previous research work. In 2000, Chong and Lee [5] used a genetic algorithm to optimize the gearing parameters of a two-stage gear train. Their choice of a stochastic algorithm is still state of the art for high-dimensional problems, since deterministic algorithms perform poorly on such problems and tend to converge to local optima. Furthermore, the design parameters of a gearbox require a mixed integer optimization (e.g. discrete number of teeth and real-valued face widths), for which the application of derivative-based methods is not sufficient [6].

The layout process of a gearbox for electric vehicles must consider multiple design objectives, such as minimizing cost as well as maximizing efficiency. Chong and Lee [5] and also the more recent work of Chandrasekaran et al. [7] treated the optimization problem as multi-objective. They used a weighted-sum-method to transform the multiple objectives into one objective function-thus transforming a multi-objective problem into a single-objective one. As pointed out by Deb and Jain [8], a weighted-sumapproach can be highly restrictive to the optimization process as the weights have to be defined a priori. There is no way to determine if even a slight change in weights might have resulted in a more favorable solution. A legit multiobjective optimization therefore always aims to find the socalled Pareto front [8] of the optimization problem. The Pareto front, named after Italian engineer and economist Vilfredo Pareto, consists of all possible sets of design parameters that result in a non-dominated solution (Pareto dominance). Non-dominated in this context refers to solutions for which no single objective value can be improved without worsening at least one of the others.

Regarding the system analysis process, most published works focusing on gearbox optimization use simplified calculation schemes for machine elements. This generally lowers the computational effort for the optimization, but at the same time it seriously lowers the quality of the result. This behavior is in strong conflict with the aim to provide a solid basis for low-risk design decisions. In this context, the system analysis process, as a state-of-the-art design method as described in [9], must implement up-to-date calculation schemes based on current standards and guidelines like ISO 6336 for the load capacity calculation of gears.

Another aspect that is rarely considered in published works is a holistic approach to the optimization problem. Gearing parameters only are considered in an exemplary manner for the optimization in [5, 7] and [8], omitting in- 
Table 1 Gearbox design parameters

\begin{tabular}{|c|c|c|c|c|}
\hline $\begin{array}{l}\text { Com- } \\
\text { ponent }\end{array}$ & Name & $\begin{array}{l}\text { Variable(s) in } \\
\text { Fig. } 4\end{array}$ & Comment & Range \\
\hline \multirow[t]{5}{*}{ Gears } & Number of teeth & $z_{1 \mathrm{I}}, z_{2 \mathrm{I}}, z_{1 \mathrm{II}}, z_{2 \mathrm{II}}$ & For each gear & Problem-dependent \\
\hline & Normal module & $m_{\mathrm{nI}}, m_{\mathrm{nII}}$ & For each gear stage & Problem-dependent \\
\hline & Profile shift & $x_{1 \mathrm{I}}, x_{2 \mathrm{I}}, x_{1 \mathrm{II}}, x_{2 \mathrm{II}}$ & For each gear & Problem-dependent \\
\hline & Helix angle & $\beta_{\mathrm{I}}, \beta_{\mathrm{II}}$ & For each gear stage & Problem-dependent \\
\hline & Helix direction & - & For each gear stage & Left-hand, right-hand \\
\hline Bearings & Bearing selection & $\begin{array}{l}\text { type, } \\
\text { row, } \\
\text { bore code }\end{array}$ & $\begin{array}{l}\text { Bearing } 1 \text { type } \\
\text { fixed to grooved } \\
\text { roller b.; } \\
\text { Bearing } 3 \& 4 \text { type } \\
\text { fixed to conical } \\
\text { roller b. }\end{array}$ & $\begin{array}{l}\text { Type of grooved ball/ } \\
\text { cylindrical roller/ } \\
\text { conical roller bearing }\end{array}$ \\
\hline Shafts & Axial offset & $w_{1}, w_{2}$ & $\begin{array}{l}\text { For input and inter- } \\
\text { mediate shaft }\end{array}$ & Problem-dependent \\
\hline \multirow[t]{2}{*}{$\begin{array}{l}\text { Geo- } \\
\text { metri- } \\
\text { cal }\end{array}$} & $\begin{array}{l}\text { Intermediate shaft } \\
\text { arrangement }\end{array}$ & - & $\begin{array}{l}\text { Deflection of inter- } \\
\text { mediate shaft }\end{array}$ & $\begin{array}{l}\text { Clock-wise, counter-clock- } \\
\text {-wise (see Fig. } 2 \text { for illus- } \\
\text { tration of both variants) }\end{array}$ \\
\hline & $\begin{array}{l}\text { Total center dis- } \\
\text { tance }\end{array}$ & $a_{\text {tot }}$ & $\begin{array}{l}\text { Input- to output } \\
\text { shaft }\end{array}$ & Problem-dependent \\
\hline
\end{tabular}

fluences from the bearing selection. However, a holistic design method must consider all relevant design goals as objectives and all design parameters that significantly influence those objectives as optimization parameters. In recent work, a holistic optimization approach for electrified powertrains is presented by Albers et al. [10] that focuses on battery, power electronics, electric motor and drivetrain. It outlines a general methodology on how the system interactions can be modeled. However, a specific design method and optimization strategy is not discussed there.

Package restrictions are critical in the design of automotive components. However, published works on gearbox optimization neglect this aspect or use only simple geometrical models to estimate the package influence.

In contrast to the published work, the presented approach enhances the state of the art by

- applying a proper multi-objective optimization (instead of a transformation to a single-objective optimization by weighted-sum),

- synthesis on gearbox system level to find global optima,

- using industry-standard component calculation schemes with high level of detail to ensure reliable results and

- applying 3D geometrical models for components as well as the complete gearbox system to deal with package restrictions.

\section{Methodology}

The introduced optimization process consists of a closed loop of gearbox design parameters selection and subsequent gearbox analysis (Fig. 3). The gearbox design parameters (Fig. 4 and Table 1) fully define a specific gearbox vari- ant. These parameters are set by a stochastic differentialevolution algorithm. Therefore, there is no explicit strategy on how to deal with the interactions of the individual gearbox components. This is contrary to conventional, manual design guidelines, which recommend a certain (usually recursive) sequence of macroscopic layout and subsequent detailed component design. Such explicit, sequential design strategies may lead to suboptimal results, since the variety of design options is strongly reduced. Instead, when using the optimization approach, the feasibility of given design parameters is checked by the gearbox analysis model and, if positive, their impact on the objectives is evaluated. The set of feasible solutions is compared regarding the multiple objectives in form of a Pareto-front, to show the tradeoffs from which the decision-makers can choose the best suitable solution. So in multi-objective optimization, there is no need to explicitly balance optimization targets in form of weighting factors. The objectives for optimization are minimization of

- the losses (corresponding to maximization of efficiency),

- the package metric (described in the following section) and

- the overall costs.

Depending on the problem-specific requirements, additional objectives can be added, as any property derivable from the gearbox can be used as optimization objective. In the demonstrated case study, this will be axial width, ground clearance and lateral width of the gearbox.

Constraints to the optimization problem are the

- requirements regarding the total center distance and the total gear ratio as well as 
- sufficient safety factors and lifetime of machine elements (shafts, gears, bearings) with respect to the given load spectrum,

- geometrical feasibility (see following section 'Internal collision checking') and

- adherence of basic design guidelines for gears in automotive applications to accomplish smooth running (see following section 'Gear geometry').

\section{Gearbox analysis}

The gearbox design parameters serve as inputs for the gearbox system analysis, which implements a successive calculation of system properties and checking of constraints. The idea behind this is that invalid gearbox variants (invalid due to constraint violation) are identified as early and with the least computational effort as possible. The aim here is to reduce the number of extensive calculation steps, e. g. of gear load capacity or package-related metrics to increase optimization performance. A flow chart representing the major steps of the system analysis process is shown in Fig. 5. The applied calculation schemes of system properties determination include:

a) Gear geometry

The gear geometry is calculated according to Köhler/ Rögnitz [11] and Linke/Börner/Heß [3], which are both based on the industry standard DIN 3960. The width of the gear wheels $b$ for each stage is determined by a predefined overlap ratio $\varepsilon_{\beta}=2$, which is recommended for smooth operation [11]. The gear wheel width is thus not implemented as an independent gearbox design parameter but calculated by the normal module $m_{\mathrm{n}}$ and the helix angle $\beta$ (Eq. 1).

$\varepsilon_{\beta}=2 \rightarrow b=\varepsilon_{\beta} \cdot \pi \cdot m_{\mathrm{n}} / \sin (\beta)$

b) Shaft geometry

The shafts are designed as hollow shafts with a fixed ratio of inner and outer diameters. The outer diameters depend on geometrical restrictions resulting from the gear design and the bearing selection, which are both determined by the design parameters. In particular, the gear's tooth root diameter and the bearings' inner diameter are considered to ensure geometrical compatibility of the shaft with the gear and the bearing, respectively. The shafts' axial lengths are determined by the design parameters $w_{1}$ and $w_{2}$ and the widths of the gears and the bearings (Fig. 4). The mechanical torsional strength of the shafts is checked, although this is not critical in most cases.

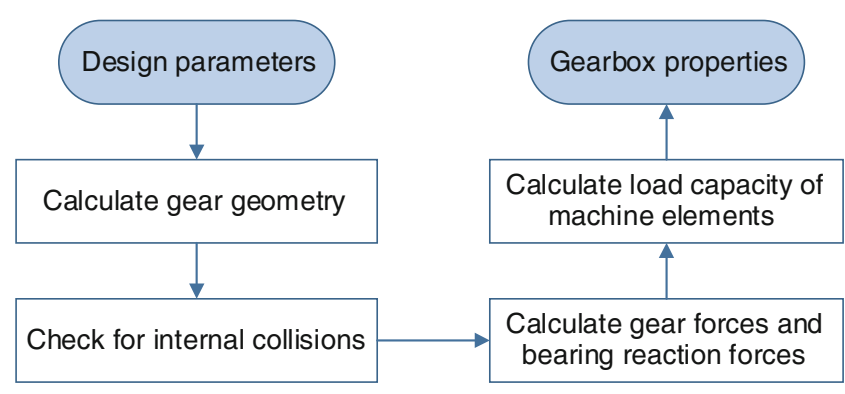

Fig. 5 Major steps in the gearbox system analysis process

The radial contour of the output shaft also contains the shape of the differential drive, which is selected off-theshelf depending on the required transmittable torque.

c) Shaft arrangement $\&$ statics (bearing reaction forces)

The center distances of the first and second stage result from gear-related design parameters, while the total center distance between input- and output shaft is explicitly defined as a design parameter (Table 1). Depending on the design problem definition, the total center distance is defined to be constant or within a specified range. A Boolean design parameter decides in which direction the intermediate shaft is aligned (see Fig. 2 for an illustration of both variants), which affects the resulting forces and the gearbox package. Shafts are modeled as rigid bodies and pressure angles of conical roller bearings are considered for the calculation of the resulting forces.

d) Bearings' static safety factor and lifespan

The bearings' static safety factor and lifespan is determined according to ISO 281 and the bearing manufacturer scheme [12] considering the load spectrum.

e) Internal collision checking

During the search for beneficial gearbox solutions, the optimization algorithm varies the gearbox design parameters. Certain value combinations can lead to a gearbox system that is physically not meaningful. An example is that the bull gear on the intermediate shaft might be too large and collide with the contour of the output shaft. In this way, invalid suggestions are identified by evaluation of polygon intersections of the radial contour of the shaft assemblies.

f) Gear load capacity

The gear load capacity is calculated according to ISO 6336 considering tooth root fatigue and pitting.

g) Efficiency

The modelled gearbox efficiency results from load- and speed-dependent gear- and bearing losses for the given load spectrum. The gear efficiency is calculated according to Linke/Börner/Heß [3] and bearing losses are determined according to the bearing manufacturer scheme [12]. 
Fig. 6 Visualizaton of the package metric for a no package violation, $\mathbf{b}$ violation of desired installation space
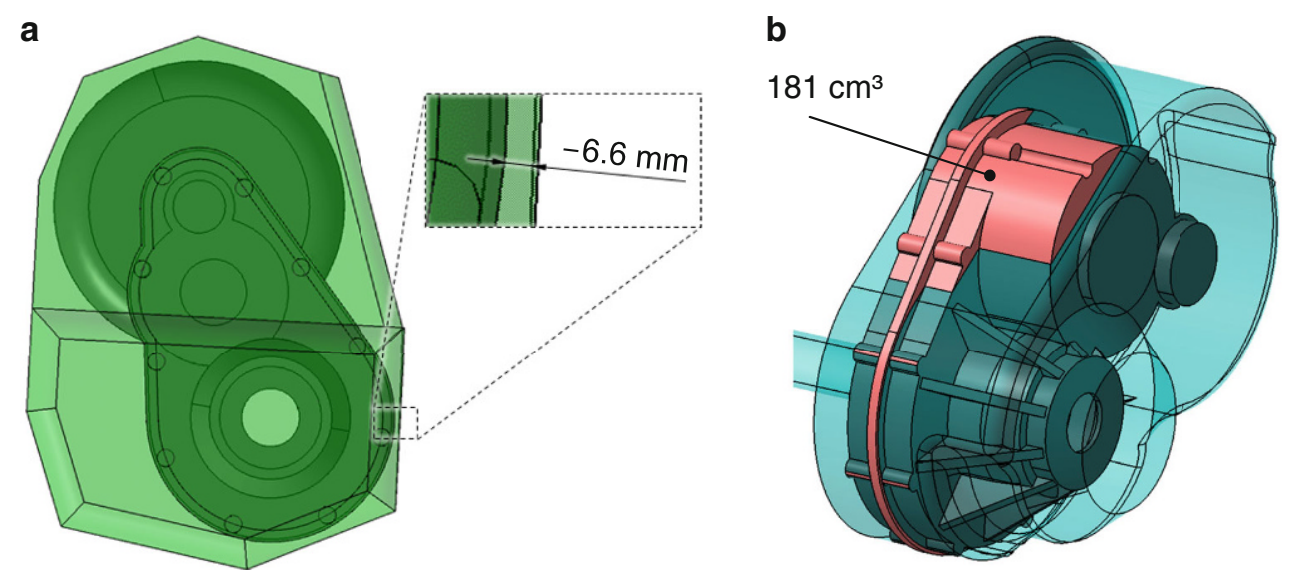

h) Costs

For shafts, gears and housing, a mass-specific cost factor is applied for each component type, considering the applied material. The bearing costs are taken from a supplier catalogue [13, 14].

i) Package

To evaluate the package integration, a parametric 3Dmodel of the gearbox including the housing is applied [15]. It automatically generates the geometrical shape of the housing as a function of shaft- and gear wheel dimensions as also of the bearing arrangement. The package integration of the gearbox is then quantified by a specific package metric, depending on two cases:

a. If the gearbox solution completely fits inside the desired installation space, the negative value of the minimum clearance between the gearbox and the installation space is measured (Fig. 6a).

b. If the gearbox solution violates the desired installation space, the violating volume is measured (Fig. 6b).

This definition enables the coverage of both cases with a single scalar value, where smaller values are beneficial.

\section{Results}

\subsection{Case study}

The proposed gearbox design method is exemplarily demonstrated in the context of a complete eDrive development challenge. Focussing on the gearbox layout process, the electric machine and inverter setup are kept constant. The requirements on the gearbox are derived from electric machine properties and required driving performance (Table 2). The layout process considers a given load spectrum for bearings and gears as also for the evaluation of efficiency characteristics.
Table 2 Main requirements of the demonstration gearbox design problem

\begin{tabular}{ll}
\hline Total center distance & $165 \mathrm{~mm}$ \\
Total transmission ratio & $9.32 \pm 1 \%$ \\
Nominal input torque & $366 \mathrm{Nm}$ \\
Max. input speed & $15,000 \mathrm{rpm}$ \\
Required service life & $944 \mathrm{~h}$ \\
Material of shafts \& gears & $20 \mathrm{MnCr} 5$ \\
\hline
\end{tabular}

The desired gearbox installation space is highly challenging (Fig. 1b), as even the benchmark design does not fully comply with it. Later it will be shown in Fig. 8 that there is no feasible solution for the predefined material selection of gears and shafts (Table 2). Therefore, it is intended to find the best solution in terms of violating the predefined volume. The solutions found by the optimization algorithm are compared with a benchmark gearbox design (Fig. 1a). For a detailed evaluation of the packaging concept, the parameters of the benchmark solution are used to parametrize the generic housing model (Fig. 1b). This model is also used to evaluate the solutions found by the optimization algorithm and therefore comparability between the optimization results and the benchmark solution is provided.

It is important to keep in mind that the benchmark gearbox represents a completely engineered solution, which also considers specific detailed design characteristics, e. g. lubrication, deformation of the housing, NVH, rotor stability and park lock integration. These detailed aspects are not considered in the introduced conceptual gearbox layout method. Therefore, the comparison can only give an indication of the layout and objective values must be compared with care.

The optimization targets for this study are formulated to minimize

a) costs,

b) losses, 
Fig. 7 2D-subsets of the Pareto-front representing ground clearance metric (tip radius of gear on output shaft) as a function of a package metric and b costs

Fig. 8 Optimization result: 3D-Pareto front (top-right) regarding package metric and costs compared to benchmark solution ('REF')

Table 3 Selected design options compared to benchmark design (all 20MnCr5) 2D-Pareto subset (circles) of a

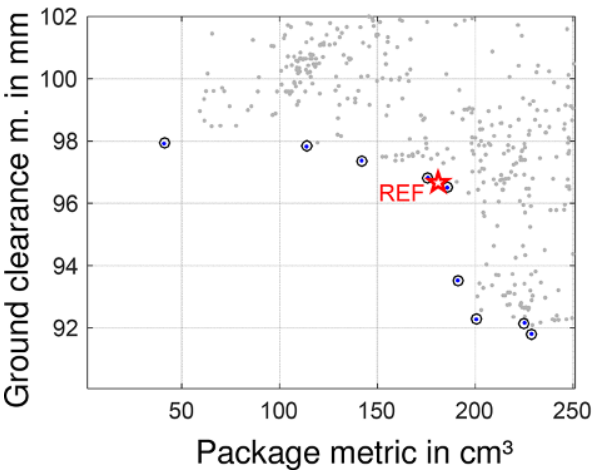

b

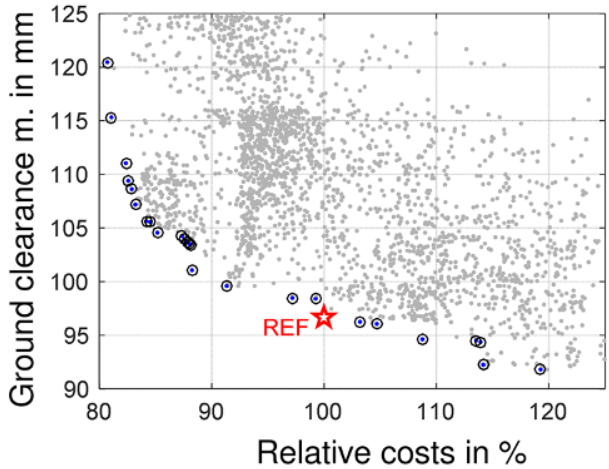

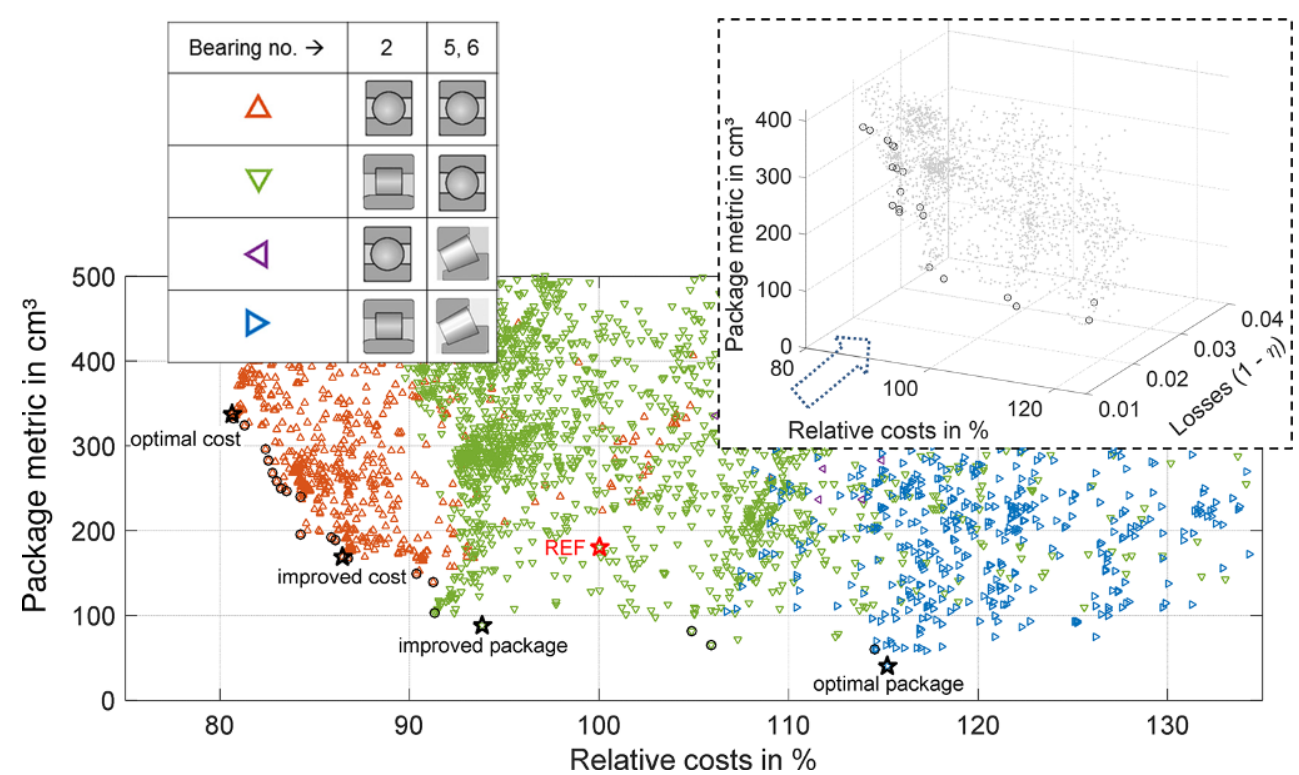

\begin{tabular}{llllll}
\hline & Benchmark & Impr. cost & Impr. package & Opt. cost & Opt. package \\
\hline Package metric in $\mathrm{cm}^{3}$ & 181 & 169 & 89 & 332 & 41 \\
Relative costs & $100 \%$ & $-13 \%$ & $-6 \%$ & $-19 \%$ & $+15 \%$ \\
- Shafts \& gears & $100 \%$ & $+5 \%$ & $+2 \%$ & $+20 \%$ & $-2 \%$ \\
- Bearings & $100 \%$ & $-21 \%$ & $-8 \%$ & $-33 \%$ & $+22 \%$ \\
- Housing & $100 \%$ & $+5 \%$ & $-3 \%$ & $+16 \%$ & $-5 \%$ \\
Bearing 1 & 6206 & 6307 & 6207 & 6207 & 6306 \\
Bearing 2 & NU205-E & 6207 & NU304-E & 6307 & NU205-E \\
Bearing 3 & 32010 & 32008 & 32008 & 32007 & 33206 \\
Bearing 4 & 32010 & 32009 & 32009 & 32007 & 32010 \\
Bearing 5 & 6012 & 6212 & 6212 & 6211 & 32010 \\
Bearing 6 & 6011 & 6011 & 6010 & 6010 & 32010 \\
\hline
\end{tabular}

c) axial width of the gearbox,

d) gear tip radius on the output shaft (related to ground clearance, later called 'ground clearance metric') and

e) lateral width of the gearbox (related to the eccentricity of the intermediate shaft).

After the main optimization process, a post-processing step evaluates the introduced

f) package metric. The available degrees of freedom regarding gearbox installation positions and angles are examined by an independent optimization procedure to find the optimal arrangement for each gearbox variant. 
a

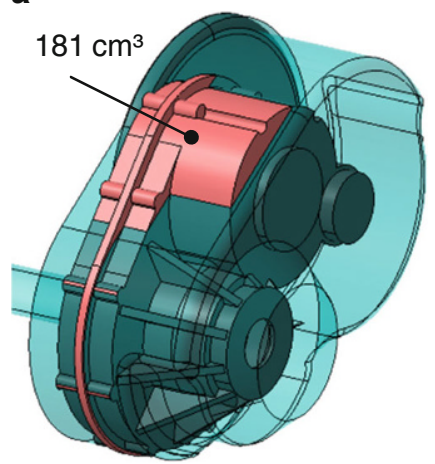

b

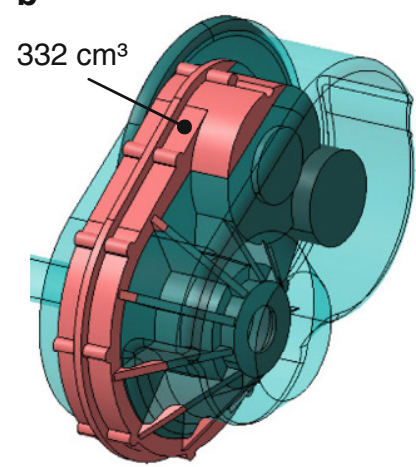

C

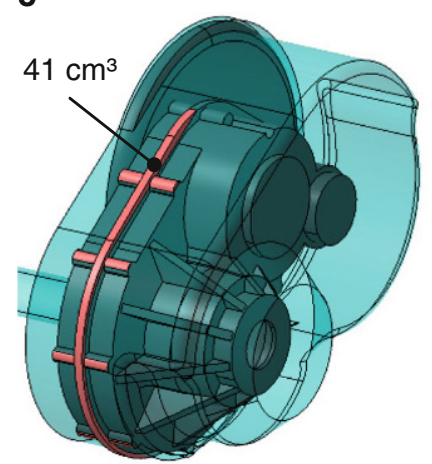

d

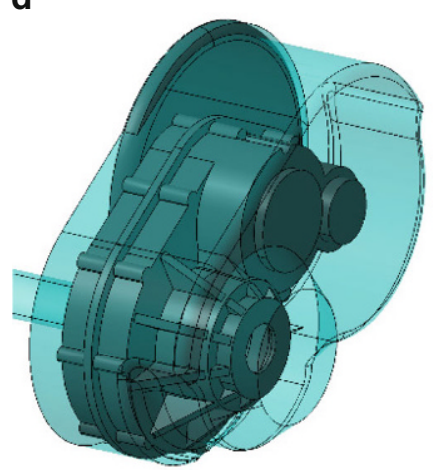

Fig. 9 Comparison of package situation for a benchmark solution (20MnCr5); b cost-optimal solution (20MnCr5); c package-optimal solution (20MnCr5); d package-optimal solution (high-strength material 18CrNiMo7-6)

This sequence of process steps boosts optimization performance, since the packaging-related optimization targets c) to e) are calculated with analytic expressions independently from the desired installation space. With this method, the process of packaging investigations, which requires high computational effort in a 3D-CAD software, is only executed for the Pareto-optimal results regarding the objectives a) to e). Furthermore, the analytic package-related expressions allow the decision-maker to prioritize certain locations of package violations.

\section{Selected results}

The benchmark gearbox considered would appear to be designed as a good tradeoff between ground clearance, violating installation space volume and costs ('REF' in Fig. 7).

In the top right corner of Fig. 8, the 3D-Pareto front regarding package metric, costs and losses is depicted. When analyzing the Pareto subset of the package metric and the costs (Fig. 8), several improvement options arise (Table 3). Compared to the benchmark solution, both costs and package metric could be improved.

The Pareto-front of package and costs is strongly influenced by the selection of bearings. Fig. 8 shows that grooved ball bearings lead to cost-effective but larger solutions, cylindrical roller bearings and conical roller bearings are more expensive but allow a more compact design. In Fig. 9 the extrema of cost-optimal and package-optimal solutions are depicted.

However, the results indicate that with given requirements it is not possible to fully comply with the desired installation space. To address this issue, the best suitable solutions may be used to discuss an adaptation of the desired installation space with the customer or other involved parties to initiate another loop of optimization with changed requirements. Another option is to extend the search space by including high-strength materials for shafts and gears, which results in more compact solutions for this case study (Fig. 9d).

\section{Outlook}

The approach is presented for the topology of a singlespeed, two-stage helical gearbox with an integrated differential drive. Future work will consider expanding the methodology to more general topologies, especially allowing more than two gear stages and other shaft arrangements.

Currently, to demonstrate the methodology, a massspecific cost model is used for shafts, gears and housing. A more detailed cost model could further improve the validity of cost tradeoffs.

The gearbox is part of the electric powertrain system, also containing the electric machine and the power electronics. To address the multi-objective optimization design problem on powertrain level, a synthesis process based on component-specific Pareto solutions can be applied [2].

\section{Summary and conclusion}

A computer-aided gearbox design optimization process is introduced to support decision-making in the early development phase. To effectively deal with the conflicting objectives, a gearbox system perspective is applied to ensure well-balanced decisions in the design of each sub-component. The gearbox design parameters and system analysis procedure are described by an example of a single-speed, two-stage helical gear with an integrated differential drive. Well-established industry standards are applied for detailed component modelling and a generic CAD-model is used to estimate and quantify the space requirements of each gearbox variant.

The introduced methodology is demonstrated on a real eDrive application scenario and compared with a bench- 
mark solution. The results indicate that a further improvement of the benchmark solution is possible, especially in view of the tradeoff between packaging and costs. By this means the introduced methodology is able to support layout processes of gearboxes taking complex and conflicting requirements into consideration. Nevertheless, the expertise of an experienced gearbox manufacturer is vital in the development of competitive gearboxes in terms of reliability, efficiency, NVH and costs. The core competences in these areas can be complemented by the proposed optimization methodology to significantly reduce development time and improve result quality in early development stages.

Acknowledgements This work is supported by Magna International and Magna Powertrain. To reduce development time and effort in future, Magna Powertrain is investigating a holistic optimal design approach for electric drive systems in co-operation with Graz University of Technology. This method supports early development stages by solving conflicts between efficiency, performance, package, weight and costs. It offers engineers and decision makers a quantitative basis to process specific product characteristics with respect to individual requirements and priorities. The presented gearbox design methodology is part of this project focusing on eDrive system perspective $[1,2]$, also including the electric machine and the power electronics.

Funding Open access funding provided by Graz University of Technology.

Open Access This article is distributed under the terms of the Creative Commons Attribution 4.0 International License (http:// creativecommons.org/licenses/by/4.0/), which permits unrestricted use, distribution, and reproduction in any medium, provided you give appropriate credit to the original author(s) and the source, provide a link to the Creative Commons license, and indicate if changes were made.

\section{References}

1. Hofstetter M, Hirz M, Ackerl M (2016) System design optimization of xEV-axle drives with package restrictions. In: Proceedings of the FISITA 2016 world automotive congress
2. Hofstetter M, Hirz M, Gintzel M, Schmidhofer A (2018) Multiobjective system design synthesis for electric powertrain development. In: 2018 IEEE Transportation Electrification Conference and Expo (ITEC). Long Beach. https://doi.org/10.1109/ITEC.2018. 8450113

3. Linke H, Börner J, Heß R (2016) Cylindrical gears: Calculation Materials - Manufacturing. Carl Hanser, Munich

4. Storn R, Price K (1997) Differential evolution-A simple and efficient heuristic for global optimization over continuous spaces. J Glob Optim 11(4):341-359

5. Chong TH, Lee JS (2000) A design method of gear trains using a genetic algorithm. Int J Korean Soc Precis Eng 1(1):62-70

6. Koziel S, Yang X-S (2011) Computational optimization, methods and algorithms. Springer, Heidelberg

7. Chandrasekaran M, Padmanabhan S, Srinivasa Raman V (2015) Single speed gearbox optimization using genetic algorithm. J Eng Appl Sci 10(13):5506-5511

8. Deb K, Jain S (2003) Multi-speed gearbox design using multi-objective evolutionary algorithms. J Mech Des N Y 125:609-619

9. Parlow J, Otto M, Stahl K (2016) From specification to gearing-application specific gear box design using an explicit design model. Konstruktion 68(3):64-69

10. Albers A, Bause K, Reichert U, Ott S (2017) The development of electric drive systems-How to deal with the challenges. In: EVS30: the 30th international electric vehicle symposium \& exhibition.

11. Künne B (2008) Köhler/Rögnitz Maschinenteile vol 2. Vieweg+ Teubner, Wiesbaden

12. Schaeffler Technologies AG \& Co. KG (2014) Technische Grundlagen und Produktdaten zur Gestaltung von Wälzlagerungen. https:// www.at.schaeffler.com/remotemedien/media/_shared_media/08_ media_library/01_publications/schaeffler_2/catalogue_1/downloads _6/hr1_de_de.pdf. Accessed 16 July 2018

13. Kugellager - Direkt Ltd. \& Co KG (2018) kugellager-direkt.de. http://www.kugellager-direkt.de/. Accessed 16 July 2018

14. Kugellager-online GmbH \& Co. KG (2018) ekugellager.de. https:// www.ekugellager.de. Accessed 16 July 2018

15. Pichler M (2018) Parametrisches Gehäusemodell eines Stirnradgetriebes für elektrifizierte Fahrzeuge. Institute of Automotive Engineering, Graz (Bachelor Thesis) 